\title{
MJN EFFECTIVENESS OF AN EDUCATION PROGRAM ON KNOWLEDGE AND SELF CARE PRACTICES OF ADOLESCENT STUDENTS WITH PREMENSTRUAL SYNDROME IN ERBIL CITY
}

\author{
Sazan Bahram Ahmed*, Awaz Aziz Saeed \\ Maternity Department, College of Nursing, Hawler Medical University, Egypt \\ *Corresponding Author's Email: sazan.ahmed@hmu.edu.krd
}

\begin{abstract}
Background: Pre-menstrual syndrome is recurrent troublesome physical and emotional symptoms that develop 7-14 days before the onset of menstruation and subsides when menstruation occurs. Methods: A quasi-experimental study was conducted in intermediate and secondary schools in Kurdistan region from 1st January 2018 to $15^{\text {th }}$ January 2019 to identify the effectiveness of health education programs on adolescent students' knowledge and practices regarding premenstrual syndrome. A purposive sample of 200 students aged 13-20 years was selected. A questionnaire format was constructed. Two hundred students were interviewed to participate in the study and divided into two groups. The educational program was done for the intervention group. Data analysis was done through the use of the statistical package of social science, version 23. Results: The overall students' knowledge concerning premenstrual syndrome after the implementation of educational intervention improved and the percentage increased from $24.1 \%$ at pre-test to $56.3 \%$ at post-test, while the percentage was not improved in the comparison group. Conclusion: The results revealed the effectiveness of the program in improving the knowledge and practices of students in the intervention group. The study recommends to the Ministry of education that educational programs regarding premenstrual syndrome must be included in the curriculum of the school.
\end{abstract}

Keywords: Premenstrual Syndrom; Education; Adolescent; Knowledge; Self-care

\section{INTRODUCTION}

Adolescence is the developmental period occurring between childhood and adulthood. It is a transitional period marked by substantial changes in physical maturation, cognitive abilities, and social interactions (Laird, 2013). PM refers to the periodic recurrence of a combination of physical, psychological, and behavioral changes in the luteal phase of the menstrual cycle, which is one of the prevalent problems among women (Zendehdel \& Elyasi, 2018). It is estimated that up to $75 \%$ of premenopausal women experience some physical or emotional symptom in the two weeks before menses begins. Common premenstrual symptoms range from emotional and behavioral symptoms such as depression, angry outbursts, irritability, crying spells, anxiety, confusion, social withdrawal, poor concentration, sleep disturbance, and thirst and appetite changes, to physical symptoms including breast tenderness, bloating and weight gain, headache, swelling of the hands or feet, and aches or pains (KrollDesrosiers et al., 2017). The causes of PMS are unclear, though an underlying neurobiological vulnerability to normal fluctuations in the circulating sex hormones levels during the menstrual cycle is thought to contribute. Hormonal fluctuations may also alter brain neurotransmitters or neuropeptide function, contributing to both emotional and physical symptoms (Daley, 2009). Premenstrual syndrome (PMS) occurs 7-14 days before the onset of menstruation and subsides with the commencement of menstrual flow. It is associated with physical, psychological and behavioral changes (Ramya et al., 2004). PMS and PMDD are not the same. Women with PMDD have more severe symptoms that have a significant impact on their daily functions. The two may occur together, or a woman may have one and not the other (Stoppler, 2016).

PMS has been studied and evaluated extensively in the West and only a handful amount of research studies 
have been conducted in Asia (Saeed \& Mohammed, 2016). Management of premenstrual syndrome in young, aged women focuses on pharmacological treatments for PMS in the form of hormonal interventions, antidepressants, high-dose estrogen as transdermal patches or subcutaneous implants, non-steroidal antiinflammatory drugs for severe degrees. Also, positive coping techniques and lifestyle modifications are often recommended for alleviated severity of physical and psychological symptoms of PMS especially among mild and moderate degrees in the form of yoga, exercises, with dietary changes through; supplements of vitamins (A, E, and B6); calcium; magnesium; multivitamin/mineral supplements (Elnagar \& Awed, 2015).

Nowadays, there is more effort in evaluating education programs in terms of improvement in individuals' health status including physical and psychological well-being. A major goal in health education is also to promote better health. Some scholars argue that when PMS in adolescents is ignored, it can cause an impact on the adolescents' health and quality of life (Shobeiri et al., 2017). A health education program was evaluated to determine its efficacy in increasing knowledge about menstrual cycle and management of premenstrual syndrome (PMS) through home remedies with simple kitchen herbal recipes, diet control and breathing exercise along with education on anatomy and physiology of the female reproductive system (Norwitz \& Schorge, 2001).

It is noted from the researcher's experience that adolescent girls in Erbil city generally had a lack of knowledge about premenstrual syndrome and proper self-care practices to manage premenstrual symptoms which might affect their reproductive health. Therefore, this study intends to find out the effects of adolescent health education on students' knowledge and self-care practices regarding the premenstrual syndrome.

\section{METHODOLOGY}

A quantitative (quasi-experimental) study was used to assess knowledge and self-care practices and to evaluate the effectiveness of educational programs regarding premenstrual syndrome through the period from February to May 2018 at four schools according to geographical location and number of samples in Erbil city in the Kurdistan Region of Iraq. A non-probability, purposive sample size of 200 adolescent students was chosen. 50 students were chosen from each school as intervention group (100) and comparison group (100) samples with premenstrual syndrome (PMS). Diagnostic of PMS based on American College of Obstetricians and Gynecologists criteria for diagnosing premenstrual syndrome as the national institute of mental health that must be present in the five days before menses for at least three previous menstrual cycles in a row, end within four days after of the onset and must be present in the absence of any pharmacologic therapy, hormone ingestion, or drug or alcohol use (ACOG, 2015). Girls who have not attained menarche, have irregular menstrual cycles, are suffering from chronic diseases, and are taking hormonal therapy or antidepressants were excluded. The data were collected through a direct interview by the researcher.

For the purpose of the present study, a questionnaire format was constructed through a review of literature and related studies, and background experience. The questionnaire comprised of five main parts - part one includes socio-demographic characteristics of the adolescent students such as age, marital status, a parent's level of education, parent's occupational state, height and weight and family history with PMS. Height and weight were obtained for each student. Height was taken by asking the student to stand in the front of the wall then a mark was taken then by using measuring tape the height was obtained in $\mathrm{cm}$ (centimeter); on the other hand, the weight was obtained by asking the student to remove her shoes then step on the weighing scale to measure her weight in kg. The Body Mass Index (BMI) was calculated by the following equation: $\mathrm{BMI}=$ [Weight $/ \mathrm{kg}$ ] [Height $/ \mathrm{m}]^{2}$. Part two includes characteristics of menstruation including age at menarche, cycle length, number of pads changes daily and duration of menstruation. Part three includes the severity of premenstrual symptoms assessment according to the standards of American College of Obstetricians and Gynecologists. The students were asked to rate 19 symptoms commonly found in PMS on a three-point scale with responses ranging from $1=$ mild, $2=$ moderate, $3=$ severe disabling with regard to the degree of interference and disruption to usual family, school, and social activities. Part four includes 11 questions related to knowledge regarding premenstrual syndromes such as definition, cause, factors associated with PMS, signs and symptoms, and ways to reduce PMS symptoms. The responses of the knowledge items were included two answers $(0=$ Incorrect and $1=$ Correct). The calculation of the overall levels of knowledge (11 items) was categorized into three groups 
of Poor knowledge (0-3), Fair knowledge (4-7), and Good knowledge (8-11). Part five contains the items related to self-care practice assessment which includes care for PMS, used dietary changes, exercise, mindbody interaction, and medication. The responses of the management and self-care practice items were included three answers $(0=$ Never, $1=$ Sometimes and $2=$ Always $)$. The calculation of overall levels of practice (10 items) was categorized into three groups of Never practiced ( 0 6), Sometimes practiced (7-13), and Always practiced (14-20). A health education program was organized in two sessions for each student within the group. The time allocated for each session was about 45 minutes, held in the morning. The educational session was started immediately after pre-test completion.

The program was finished in 2 weeks for each school. The validity of the questionnaire was checked initially by a panel of 12 experts from different fields. The expert responses were based on agreement or disagreement with items of the questionnaire. The results indicated that all experts agreed with the content of the questionnaire with some modifications. A pilot study was conducted on 20 participants that were not included in the final study, in order to determine the reliability of the questionnaire (internal consistency by split-half). The alpha correlation coefficient was 0.792 , which is statistically adequate. Formal administrative approval was obtained from the directorate of Education/Ministry of Education in Kurdistan Region and permission to carry out the study was obtained from relevant school authorities for the purpose of data collection. Informed oral consent was obtained from each participant. In addition, the researcher told each participant that their participation was voluntary, and that they were free to leave at any time. After data collection, the variables and data were entered into the statistical application (Statistical Package for Social Science - SPSS Version 23). The data were analyzed using SPSS software that included descriptive statistical analysis (Frequency, Percentage, Mean, and Standard Deviation) and (T. test: Paired t. test and independent $t$. test) to compare between intervention and comparison group regarding knowledge and self-care practices among the study sample.

\section{RESULTS}

Students who participated in the study were between grades seventh to twelfth.

Table 1: Distribution of Samples According to Their Socio-Demographic Data

\begin{tabular}{|c|c|c|c|c|c|}
\hline \multirow{2}{*}{\multicolumn{2}{|c|}{ Socio-Demographic Characteristics }} & \multicolumn{4}{|c|}{ Groups } \\
\hline & & \multicolumn{2}{|c|}{$\begin{array}{c}\text { Intervention } \\
\mathbf{n}=\mathbf{8 7}\end{array}$} & $\begin{array}{c}\text { Comparison } \\
\mathrm{n}=92\end{array}$ & \\
\hline & & & $\%$ & $\mathbf{F}$ & \\
\hline \multirow{2}{*}{$\begin{array}{l}\text { Age group/ } \\
\text { years }\end{array}$} & $13-16$ & 57 & 65.5 & 78 & 84.8 \\
\hline & $17-20$ & 30 & 34.5 & 14 & 15.2 \\
\hline \multirow{6}{*}{ Class } & $7^{\text {th }}$ & 10 & 11.5 & 27 & 29.3 \\
\hline & $8^{\text {th }}$ & 15 & 17.2 & 26 & 28.3 \\
\hline & $9^{\text {th }}$ & 14 & 16.1 & 9 & 9.8 \\
\hline & $10^{\text {th }}$ & 16 & 18.4 & 13 & 14.1 \\
\hline & $11^{\text {th }}$ & 21 & 24.1 & 17 & 18.5 \\
\hline & $12^{\text {th }}$ & 11 & 12.6 & 0 & 0 \\
\hline \multirow{6}{*}{$\begin{array}{c}\text { Mother's } \\
\text { education-al } \\
\text { level }\end{array}$} & Illiterate & 36 & 41.4 & 40 & 43.5 \\
\hline & Read and Write & 21 & 24.1 & 18 & 19.6 \\
\hline & Primary school & 22 & 25.3 & 19 & 20.7 \\
\hline & Intermediate School & 3 & 3.4 & 5 & 5.4 \\
\hline & Secondary School & 2 & 2.3 & 6 & 6.5 \\
\hline & Institute / College & 3 & 3.4 & 4 & 4.3 \\
\hline
\end{tabular}

*87: From the post-test there was 13 students are absent in intervention group.

*92: From the post-test there was 8 students are absent in comparison group.

Table 1 shows that the age of the majority of the study sample ranged between $13-16$ years old (65.5\%) for intervention and (84.8\%) for the comparison group. It was observed that less than half (41.1\%) for intervention and (43.5\%) for the comparison group of mothers' educational level was illiterate. It indicates that the majority $(80.5 \%)$ of students' mothers were housewives (unemployed) in the intervention group. 
This table revealed that more than half (62.1\%) of the students in the sample were normal weight in the intervention group. It indicates that $(59.8 \%)$ of samples had a family history with premenstrual syndrome in the intervention group, while the range of the study samples in control group was the same regarding the family history of premenstrual syndrome.

\section{Continue Table 1: Socio-Demographic Data among Samples}

\begin{tabular}{|c|c|c|c|c|c|}
\hline \multirow{3}{*}{\multicolumn{2}{|c|}{ Socio-demographic characteristic }} & \multicolumn{4}{|c|}{ Groups } \\
\hline & & \multicolumn{2}{|c|}{$\begin{array}{c}\text { Intervention } \\
\mathbf{n}=87\end{array}$} & \multicolumn{2}{|c|}{$\begin{array}{c}\text { Comparison } \\
\mathrm{n}=92\end{array}$} \\
\hline & & $\mathbf{F}$ & $\%$ & $\mathbf{F}$ & $\%$ \\
\hline \multirow{6}{*}{$\begin{array}{l}\text { Occupational State for Student's } \\
\text { Mother }\end{array}$} & Government employee & 5 & 5.7 & 8 & 8.7 \\
\hline & Special sector employee & 0 & 0 & 1 & 1.1 \\
\hline & Free work & 7 & 8 & 7 & 7.6 \\
\hline & Retiring & 2 & 2.3 & 4 & 4.3 \\
\hline & Unemployed & 70 & 80.5 & 72 & 78.3 \\
\hline & Student & 3 & 3.4 & 0 & 0 \\
\hline \multirow{4}{*}{ Body Mass Index } & Underweight & 11 & 12.6 & 15 & 16.3 \\
\hline & Normal weight & 54 & 62.1 & 52 & 56.5 \\
\hline & Overweight & 17 & 19.5 & 20 & 21.7 \\
\hline & Obese & 5 & 5.7 & 5 & 5.4 \\
\hline \multirow{2}{*}{$\begin{array}{l}\text { Family History with Premenstrual } \\
\text { Syndrome }\end{array}$} & Yes & 52 & 59.8 & 46 & 50 \\
\hline & No & 35 & 40.2 & 46 & 50 \\
\hline Total & & 87 & 100 & 92 & 100 \\
\hline
\end{tabular}

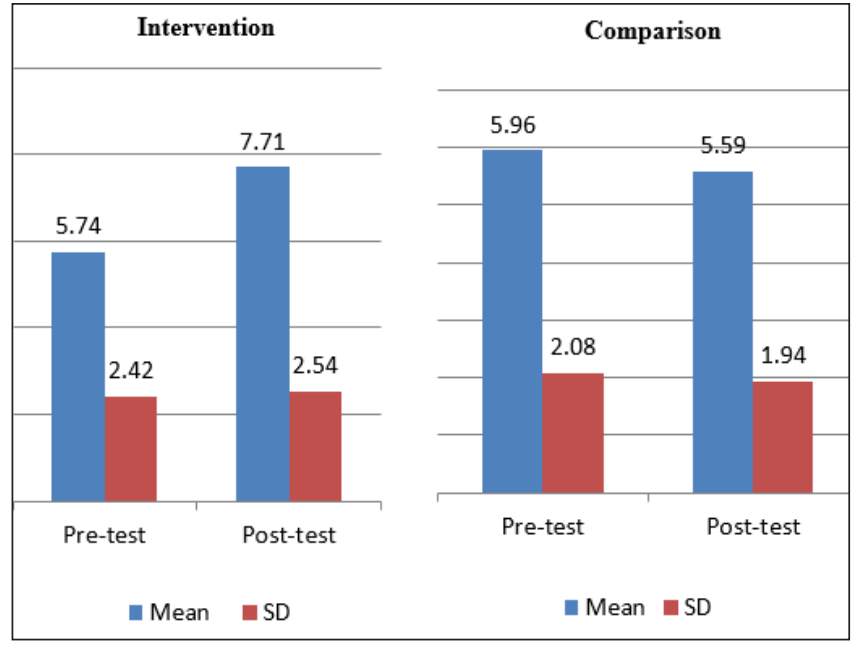

Figure 1: Comparison Between Pre-and Post-Tests of Intervention and Comparison Group Regarding Knowledge

Figure 1 illustrates a comparison between intervention and comparison groups in pre and post-test regarding knowledge among the study sample. It shows that mean scores $( \pm \mathrm{SD})$ of students' knowledge regarding premenstrual syndrome among the intervention group were increased at post-test 7.71 $( \pm 2.54)$ compared to pre-test $5.74( \pm 2.42)$, while in the comparison group the rate remains same. It indicated that there were very highly significant statistical differences between the mean score of pre and post-tests related to student's knowledge were $(P=0.001)$ among the intervention group while the difference is not significant $P$ value (0.150) at the comparison group.

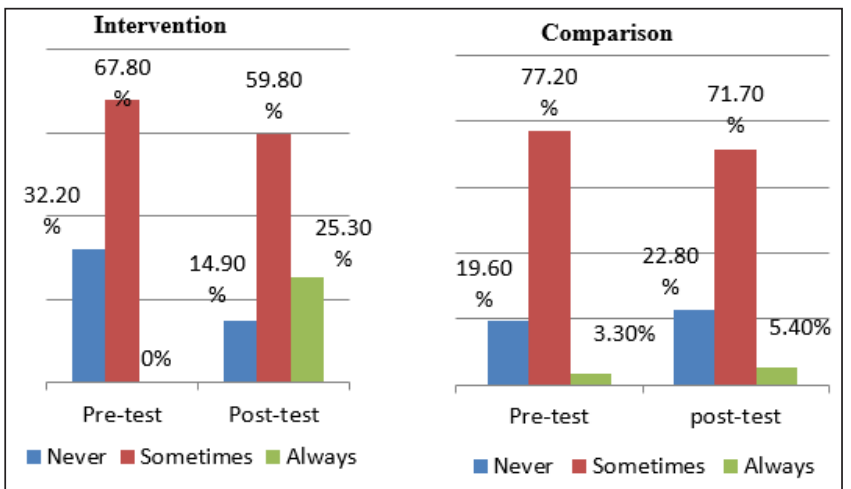

Figure 2: Distribution of Overall Self-Care Practices of Premenstrual Syndrome (Pre-Post-Test)

Figure 2 shows the overall practice scores of 
comparisons and intervention groups. A great improvement was observed in the intervention group after implementation of the educational program where the samples always self-care practice from $(0 \%)$ to $(25.3 \%)$, while the percentage nearly remains the same in the comparison group.

\section{DISCUSSION}

Based on the analysis presented in the previous chapter, the age of the majority of the samples ranged between 13-16 years in the intervention and comparison group (65.5\% and $84.8 \%$, respectively) and these results are similar to a study carried by Sarkar, Mandal \& Ghorai (2015) in India, which included 244 adolescent students in India, mentioned that $61.5 \%$ of girls were within ages 13-17 years.

Figure 1 illustrates a comparison between intervention and comparison groups in pre and post-test regarding knowledge among the study sample. The mean scores $( \pm \mathrm{SD})$ of students' knowledge concerning PMS were increased in the intervention group at posttest. It shows a very highly significant difference between pre and post-test related to students' knowledge among the intervention group while the difference is insignificant in the comparison group. This study is agreeing with our study conducted by Abdalla \& Gibreel (2016) in Saudi Arabia. It shows the mean score of students' total knowledge before and after program intervention, the total score before the program was (34.72), while after the program it was (86.28). It's indicated that a significant difference between scores before and after the program was $(P=0.000)$ (Abdalla \&
Gibreel, 2016).

Figure 2 shows the overall practice of intervention and comparison group. A great improvement was observed in the intervention group after implementation of the educational program because no anybody did self-care practices always related to PMS in pre-test while in post-test significantly increased to $(25.3 \%)$, while the percentage nearly remains the same in the comparison group. This result is agreed with a study done by Vatankhaah, Rahmani \& Hashemizadeh (2013) in Iran, he found that after training cognitive-behavioral therapy, the study group was developed general health and decreased aggression compared to the control group.

\section{CONCLUSION}

The study concluded that a very highly significant difference was observed regarding intervention group knowledge and practices in (pre-post-test). Conversely the differences are not significant in comparison group regarding their knowledge and practice in (pre-posttest). In general, after implementation of educational program the adolescent students (intervention group) knowledge and practices were improved.

\section{Conflict of Interests}

The authors declare that they have no conflict of interests.

\section{ACKNOWLEDGEMENT}

The authors are thankful to the institutional authority for completion of the work.

\section{REFERENCES}

Abdalla N.O., \& Gibreel, M.S. (2016). Effects of an educational program in increasing knowledge and reducing premenstrual syndrome signs, symptoms and severity among nursing college students. International Journal of Basic and Applied Sciences, 5(4), 200-209.

American College of Obstetricians and Gynecologists. (2015). Premenstrual Syndrome (PMS). https://www. acog.org/Patients/FAQs/Premenstrual-Syndrome-PMS?IsMobileSet=false

Daley, A. (2009). Exercise and premenstrual symptomatology: a comprehensive review. Journal of Women's Health, 18(6), 895-899.

Elnagar, M.A.E., \& Awed, H.A.E.M. (2015). Self-Care Measures Regarding Premenstrual Syndrome among Female Nursing Students. International Journal of Nursing Didactics, 5(2), 01-10.

Kroll-Desrosiers, A.R., Ronnenberg, A.G., Zagarins, S.E., Houghton, S.C, Takashima-Uebelhoer, B.B, \& BertoneJohnson, E.R. (2017). Recreational physical activity and premenstrual syndrome in young adult women: a crosssectional study. PloS One, 12(1), e0169728. 
Laird, R.D. (2013). Adolescence. Oxford University Press, UK.

Norwitz, E.R., \& Schorge, J.O. (2001). Obstetric and Gynecology at a Glance (4 ed.). Wiley-Blackwell.

Ramya, S., Rupavani, K., \& Bupathy, A. (2004). Effect of educational program on premenstrual syndrome in adolescent school girls. International Journal of Reproduction, Contraception, Obstetrics and Gynecology, 3(1), $168-171$.

Saeed, N.O, \& Mohammed, M.S. (2016). Effects of an educational program in increasing knowledge and reducing premenstrual syndrome signs, symptoms and severity among nursing college students. International Journal of Basic and Applied Sciences, 5(4), 200-209.

Sarkar, A.P, Mandal, R., \& Ghorai, S. (2015). Premenstrual syndrome among adolescent girl students in a rural school of West Bengal, India. International Journal of Medical Science and Public Health, 5(4), 773-776.

Shobeiri, F., Araste F.E., Ebrahimi, R., Jenabi, E., \& Nazari, M. (2017). Effect of calcium on premenstrual syndrome: A double-blind randomized clinical trial. Obstetrics \& Gynecology Science, 60(1), 100-105.

Stoppler, M.C. (2016). Premenstrual Syndrome (PMS). Medicine Health. https://www.emedicinehealth. com/premenstrual_syndrome_pms/article_em.htm

Vatankhaah, H., Rahmani, M.A., \& Hashemizadeh, S. (2013). The effectiveness of cognitive-behavioral training on general health and reducing aggression in women with premenstrual syndrome. Interdisciplinary Journal of Contemporary Research in Business, 4(9), 1098-1104.

Zendehdel, M., \& Elyasi, F. (2018). Bio psychosocial etiology of premenstrual syndrome: A narrative review. Journal of Family Medicine and Primary Care, 7(2), 346-356. 